\title{
CAV/EP Regimen
}

National Cancer Institute

\section{Source}

National Cancer Institute. CAV/EP Regimen. NCI Thesaurus. Code C162003.

A chemotherapy regimen consisting of alternating cyclophosphamide, doxorubicin,

vincristine with etoposide and cisplatin that may be used in the treatment of small cell lung cancer (SCLC). 